\title{
EFL College Students' Perceptions toward Native and Non-Native English Speaking Teachers
}

\author{
Shih Yun Tsou ${ }^{1}$, Ying Ling Chen ${ }^{2, *}$ \\ ${ }^{1}$ Bilingual Education, Texas A\&M University, Kingsville, United State \\ ${ }^{2}$ Center for General Education, Oriental Institute of Technology, Banqiao, Taiwan \\ *Corresponding author: cil0226@mail.oit.edu.tw
}

\begin{abstract}
The purpose of this study was to investigate Taiwanese English as a foreign language (EFL) students' perceptions and preferences toward Native English-Speaking Teachers(NESTs) and Non-Native English-Speaking Teachers (NNESTs) who hold a degree from a country where English is the dominant language through addressing the differences of their English instruction. This quantitative research was consisted of 184 participants who answered the questionnaire that involved of 28 Likert scale type statements. The results showed the teachers' qualifications and experiences were seen as an important feature of excellent English teachers, regardless of his or her mother tongue language. More precisely, NESTs were perceived to be superior in their good English proficiency and ability to facilitate students' English learning. In terms of NNESTs, they were perceived to be superior in their proficiency in students' first language, their knowledge of students' learning difficulties, and at communicating in general. Finally, the findings indicated that EFL programs where both NESTs and NNESTs worked cooperatively were considered an effective English learning environment for language learners.
\end{abstract}

Keywords: NEST, NNEST, perception, EFL

Cite This Article: Shih Yun Tsou, and Ying Ling Chen, "EFL College Students' Perceptions toward Native and Non-Native English Speaking Teachers." American Journal of Educational Research, vol. 5, no. 12 (2017): 1182-1190. doi: 10.12691/education-5-12-2.

\section{Introduction}

The craze of English language learning has swept into most of the Asian countries and Taiwan included without any exception. One of the reflections on this so called "English fever" [1] was announced by the Ministry of Education (MOE) in Taiwan, which altered the beginning of English education from the "7th grade in middle school [in 1993] to the 5th grade in elementary school in 2001 academic year and to the 3rd grade in 2005" ([2], p. 425). In addition, Yip [3] discovered that English classes offered in university programs attracted more Taiwanese college students, ranging from a bachelor degree to any graduate degrees with majors ranging from Master of Business Administration (MBA) to engineering, social sciences, and more. English is viewed as the most popular foreign language that people desire to master in Taiwan today. Most current research has been focused on whether NESTs have advantages over NNESTs in ELT. However, if we take a close look at the NNESTs, they can actually be divided into two different subgroups: NNESTs who hold a degree from a country where English is the dominant language and NNESTs who do not hold a degree from a country where English is the dominant language. It is expected that the subgroup of NNESTs holding a degree from a country where English is the dominant language get more exposure to an authentic English accent, western classroom atmosphere and western culture $[4,5]$. With all of these factors, this subgroup of NNESTs has both the advantages of NESTs who hold a degree from a country where English is the dominant language and NNESTs who do not hold a degree from a country where English is the dominant language. Whether this is true or not needs to be confirmed.

This study adopted Al-Omrani's [6] questionnaire with some modifications. Al-Omrani designed his questionnaire based on a perspective that NNESTs could be just as effective English teachers as NESTs. Originally, he insisted on the idea that native speakers of English were inherently better English teachers; he changed his mind since he was taught by a NNEST in a vocabulary class. The NNEST was familiar with students' learning difficulties, utilized appropriate teaching materials and methods of vocabulary, and provided effective strategies that were suitable for learners. The questionnaire was modified after a pilot study to fit this study, which investigated Taiwanese university students' perceptions and preferences toward NESTs' and NNESTs' English instruction.

Quantitative research questions

1. What are Taiwanese university students' perceptions in regard to the English language instruction of Native English-Speaking Teachers (NESTs) and Non-Native English-Speaking Teachers (NNESTs)?

2. From which group of teachers do Taiwanese university students prefer to learn English, Native English-Speaking Teachers (NESTs) or Non-Native English-Speaking Teachers (NNESTs) and why? 


\section{Literature}

\subsection{Native vs. Nonnative English Speaker}

As the English language expands all around the world, the term "nativeness" is actively discussed by researchers. In general, it means "who is a native speaker of English and who is not" ([6], p. 25). According to Braine [7], Ellis [8], and Mahboob [9], there is no precise definition for "native speaker," because people cannot empirically define what a native speaker is. Medgyes [10] thus, indicated that "there is no such creature as the native or non-native speaker" (p. 9). Most people believe Americans born in the U.S. to be the only native English speakers in the country. However, if we reconsider this statement, there is a group of non-Americans who attend American daycare centers or kindergarten schools, resulting in learning English before they fully acquire their parents' mother tongue. Should they be considered as native speakers of English? Also, how about those second generations of non-Americans who were born and have grown up in the U.S. and speak English with accurate American accent? hould they be categorized as native English speakers? Hence, Medgyes [10] believed that "being born into a group does not mean that you automatically speak the language - many native speakers of English cannot write or tell stories, while many non-native speakers can" (p. 18). Kramsch [11] added that "native speakership ... is more than a privilege of birth or even of education" (p. 363).

\subsection{The Controversy of the Native Speaker Ideal}

Freudenstein [12] demonstrated a policy statement, which indicated that the standard foreign language teachers within European countries should be a native speaker of a language. Ngoc [13] claimed that only native speaker teachers were capable to teach an authentic language in daily life because they had "a better capacity in demonstrating fluent language, explaining cultural connotations, and judging whether a given language form was acceptably correct or not" (p. 2). Moreover, Phillipson [14] pointed out that NESTs who had better English competence were more qualified to teach than NNESTs. Clark and Paran [15] described a hiring policy implemented among numerous ESL and EFL institutions, which emphasized only NESTs were qualified to be recruited because "students do not come to be taught by someone who doesn't speak English" ([16], p. 6).

The mystery of the native speakers was that they were better English teachers due to a better command of the English language, while the negative stereotype of the NNESTs had been widely disseminated in present day $[17,18,19]$. Admittedly, this theory has influenced the perceptions of language teachers, students, and the public, which leaves little room for NNESTs in the field of ELT.

However, there have been several arguments against this assumption [16,20-26]. These opposite opinions believed that English teachers should not be valued just by their first language. Cheng and Braine's [27] study served as an example along the same line. In their research, EFL students in Hong Kong universities were investigated for their attitudes and opinions towards NESTs and NNESTs, the pros and cons of the teachers from students' points of views, and the capability of these teachers to assist students' academic learning. The results revealed that both students and their families showed positive attitudes to Hong Kong EFL NNESTs. This surprising point contradicted a previous result [19] which had revealed the negative perceptions of students' families toward EFL teachers. Looking more closely, participants did not face any problems regarding a teacher's "nativeness;" instead, they believed that NNESTs taught EFL effectively with no genuine differences while comparing to NESTs.

\subsection{Discussion on Strengths and Weaknesses of Native English-Speaking Teachers (NESTs) and Non-Native English- Speaking Teachers (NNESTs)}

Cook [28] indicated that NNESTs "provide models of proficient [second language] users in action in the classroom, and also examples of people who have become successful [second language] users" (p. 57). Modiano's [29] study further showed that NNESTs would be more aware of learning an international variety of English and would be in a better position to encourage diversity since they did not belong to a specific variety of English. As a result, students would "learn more about how English operates in a diverse number of nation states so that they can gain better understanding of the wide range of English language usage" (p. 40).

Thus, Medgyes [30] concluded that an ideal NEST was the one who had achieved a high level of proficiency in the learners' native language; as for the ideal NNESTs, one should achieve near-native proficiency in English (p. 348). As for an ideal school, Medgyes [22] suggested that the school should have NESTs and NNESTs complemented each other in their advantages and disadvantages (p. 441).

As for the weaknesses of NESTs, Tang [31] enumerated several points: (1) different linguistic and cultural backgrounds from learners, (2) lack of the awareness of learners' needs, (3) unable to perceive the difficulties of learning the target language, and (4) unfamiliar with learners' learning contexts. Shaw [32] explained that NESTs lacked the necessary insights into lesson preparation and delivered because they were not willing to learn the host languages and cultures [33]. In Barratt and Kontra's [20] study, NESTs rarely made useful comparison and contrasts with the learner's first language and did not empathize with students going through the learning process, which discouraged learners easily. Additionally, Boyle [34] pointed out that NESTs might understand the accuracy in grammar but were not able to explain language rules like NNESTs did.

Regarding the disadvantages of NNESTs, it is undeniable that NNESTs' may not be as confident as NESTs in speaking aspects. Canagarajah [35] and Moussu [36] noted that NNESTs' higher anxiety on their accent and pronunciation greatly influenced their English instructions and the interactions, which might lead to the failure of language teaching. Tang's [31] study revealed similar results that NESTs were superior in terms of 
speaking, accents and pronunciation while NNESTs' shortcomings included the foreign accent, insufficient knowledge of American culture, and the lack of self-confidence [37].

While discussing the different teaching behaviors, Arva and Medgyes' [38] study explored the different teaching styles between NESTs and NNESTs based on their backgrounds of language, qualifications, and experiences. The results showed that NESTs tended to implement a wider variety of cultural resources and more structured activities, such as newspapers, posters, and videos, rather than a formal textbook. Besides, NESTs often failed to manage the time for class discussion and did not provide a fair opportunity for each student to participate. NNESTs, on the contrary, preferred a step-by-step approach based on course books. The atmosphere in class was formal with less interaction with students. NNESTs better explained language rules, served as a role model for students, and demonstrated how to make sense of the English language.

An easy way to comply with the journal paper formatting requirements is to use this document as a template and simply type your text into it.

The template is used to format your paper and style the text. All margins, column widths, line spaces, and text fonts are prescribed; please do not alter them. Your paper is one part of the entire proceedings, not an independent document. Please do not revise any of the current designations.

\section{Methodology}

In the study, the participants were 184 university-level Taiwanese EFL students. First, four Taiwanese universities'
English programs from northern Taiwan were randomly selected. According to Trochim [39], simple random sampling is a fair way to select a sample without bias issues, since every individual has the same opportunity of being chosen at any stage during the sampling process and researchers can generalize findings from samples and apply the results back to populations. In addition, a purposive sampling was applied for electing all the participants needed to have the experiences of learning English as a foreign language for at least seven years, and had at least two semesters learning with NESTs and NNESTs who were able to express their preferences towards their preferred teachers.

The questionnaire in the study consisted of four sections: (1) consent form, (2) key definitions, (3) Individual Background Questionnaire (IBQ), (4) statements that measure students' perceptions and preferences in regard to NESTs and NNESTs in English instruction. Quantitative data was analyzed through descriptive statistics by using Statistical Packages for the Social Science (SPSS) version 20.0 and categorized into three areas: students' learning experiences (Items 1-9), teachers' performances in English education (Items 10-26), and students' overall preferences (Items 27-28). The researcher analyzed the quantitative data by using descriptive statistics to get percentages, means, and standard deviations.

\section{Finding and Discussion}

The participants reported their perceptions in terms of their learning experiences with NESTs and NNESTs. Table 1 presents the results of items 1 to 9 .

Table 1. Percentage, Mean, and Standard Deviation of the Participants' Learning Experiences with NESTs and NNESTs

\begin{tabular}{|c|c|c|c|c|c|c|c|c|}
\hline Statements & & $\begin{array}{c}1 \\
(\mathrm{SD})\end{array}$ & 2 & 3 & 4 & $\begin{array}{c}5 \\
(\mathrm{SA}) \\
\end{array}$ & M & $\mathrm{SD}$ \\
\hline \multirow{2}{*}{ 1.I learn English better from NNESTs because we share the same first language. } & $\mathrm{F}$ & 3 & 16 & 80 & 75 & 10 & \multirow{2}{*}{3.40} & \multirow{2}{*}{.79} \\
\hline & $\mathrm{P}(\%)$ & 1.6 & 8.7 & 43.5 & 40.8 & 5.4 & & \\
\hline \multirow{2}{*}{ 2.I learn English better from NNESTs because we share the same culture. } & $\mathrm{F}$ & 1 & 21 & 78 & 75 & 9 & \multirow{2}{*}{3.38} & \multirow{2}{*}{.75} \\
\hline & $\mathrm{P}(\%)$ & 0.5 & 11.4 & 42.4 & 40.8 & 4.9 & & \\
\hline \multirow{2}{*}{ 3.I feel motivated when I take course with NNESTs. } & $\mathrm{F}$ & 6 & 49 & 97 & 27 & 5 & \multirow{2}{*}{2.87} & \multirow{2}{*}{.75} \\
\hline & $\mathrm{P}(\%)$ & 3.3 & 26.6 & 52.7 & 14.7 & 2.7 & & \\
\hline \multirow{2}{*}{ 4.I feel anxious when I take course with NESTs. } & $\mathrm{F}$ & 16 & 65 & 69 & 30 & 4 & \multirow{2}{*}{2.68} & \multirow{2}{*}{.92} \\
\hline & $\mathrm{P}(\%)$ & 8.7 & 35.3 & 38.0 & 16.3 & 2.2 & & \\
\hline \multirow{2}{*}{$\begin{array}{l}\text { 5.NNESTs are better than NESTs because they can understand my problems in } \\
\text { learning English. }\end{array}$} & $\mathrm{F}$ & 3 & 21 & 69 & 77 & 14 & \multirow{2}{*}{3.42} & \multirow{2}{*}{.85} \\
\hline & $\mathrm{P}(\%)$ & 1.6 & 11.4 & 38.0 & 41.8 & 7.6 & & \\
\hline \multirow{2}{*}{ 6.NNESTs always understand my questions and provide clear answers. } & $\mathrm{F}$ & 1 & 12 & 73 & 84 & 14 & \multirow{2}{*}{3.53} & \multirow{2}{*}{.75} \\
\hline & $\mathrm{P}(\%)$ & 0.5 & 6.5 & 40.0 & 45.7 & 7.6 & & \\
\hline \multirow{2}{*}{$\begin{array}{l}\text { 7.NNESTs are a good model in learning English because they have gone through the } \\
\text { same language learning process. }\end{array}$} & $\mathrm{F}$ & 2 & 17 & 106 & 51 & 8 & \multirow{2}{*}{3.25} & \multirow{2}{*}{.73} \\
\hline & P (\%) & 1.1 & 9.2 & 57.6 & 27.7 & 4.3 & & \\
\hline $\begin{array}{l}\text { 8.In general, intermediate and advanced learners learn better with NESTs because they } \\
\text { rely less on the Chinese support and need more opportunities to practice their English. }\end{array}$ & $\mathrm{F}$ & 1 & 13 & 58 & 83 & 29 & 3.68 & .84 \\
\hline 9.In general, beginning learners learn better with NNESTs because NNESTs apply & $\mathrm{F}$ & 3 & 20 & 59 & 85 & 17 & \multirow{2}{*}{3.51} & \multirow{2}{*}{.87} \\
\hline Chinese into English instruction. & $\mathrm{P}(\%)$ & 1.6 & 10.9 & 32.1 & 46.2 & 9.2 & & \\
\hline
\end{tabular}

Note. 1 = Strongly Disagree; 2 = Disagree; $3=$ Neutral; 4 = Agree; $5=$ Strongly Agree

$\mathrm{M}=$ Mean; $\mathrm{SD}=$ Standard Deviation; $\mathrm{F}=$ Frequency; $\mathrm{P}=$ Percentage.

Results from the above 28 statements revealed the participants' perceptions and preferences in regard to both NESTs' and NNESTs' English education.

\subsection{Research Question 1}

What are Taiwanese university students' perceptions in regard to the English language instruction of Native
English-Speaking Teachers (NESTs) and Non-Native English-Speaking Teachers (NNESTs)?

Results from items 1 to 26 showed that Taiwanese university students believed that NNESTs offered advantages to English instruction in some aspects. To be more specific, the participants stated that learning from NNESTs had the following advantages. First of all, due to the same first language and cultural backgrounds, $45 \%$ of 
the Taiwanese university students claimed they learned English better from NNESTs. That is, by sharing the same mother tongue language and cultural backgrounds, NNESTs could better understand students' problems in learning English, stated by $49.4 \%$ of the participants; NNESTs could provide clearer answers to students' questions, claimed by $53.3 \%$ of the respondents. Also, about $30 \%$ of the participants considered NNESTs went through the same language learning process like other English learners did; hence, NNESTs were deemed as good models of learning English.

Secondly, most participants in items $13,16,18$, and 19 $(54.9 \%, 57.1 \%, 57.6 \%, 57.1 \%$ respectively) agreed that NNESTs had some positive aspects in teaching the courses of writing, grammar, vocabulary, and American culture. For example, in writing courses, students could describe what they wanted to write in Chinese to NNESTs; in grammar courses, NNESTs provided Chinese explanations for the rules of English grammar; in vocabulary courses, NNESTs often offered Chinese explanations to unknown English words; in the courses of American culture, NNESTs were able to combine both Chinese and American cultures into the curriculum.

Finally, 30.9\%, 50.6\% and 36.4\% (Items 22, 24, 25, respectively) of the participants believed NNESTs created positive English learning because of the use of Chinese into English instruction, the comparisons between Chinese and English while teaching, and the abilities of using different techniques and teaching methods. Generally speaking, this kind of English instruction is better for beginning learners to learn English, stated by $55.4 \%$ of the participants.

As for the disadvantages associated with NNESTs, about $30 \%$ of the respondents claimed that they did not feel motivated when they learned from NNESTs. One of the reasons considered by $46.2 \%$ of the respondents was that NNESTs cared less about class activities, games, and out-of-class activities as resources of English learning.

Upon the same nature, the participants felt that NESTs were superior to NNESTs in the following aspects. First, the majority of the participants $(66.3 \%)$ in item 12 preferred to learn oral skills with NESTs because they saw NESTs as the most fluent speakers. This positive feature of NESTs might lead English learners to prefer NESTs over NNESTs as they allowed students to hear English as it was spoken in real settings. Furthermore, as results indicated, $71.2 \%$ of the participants considered NESTs had standard pronunciation and pronounced words more accurately. Given this, the participants might naturally believe that it was more appropriate to learn oracy from someone who spoke English as a native language.

Secondly, $65.8 \%$ of the participants showed their willingness to take oral classes with NESTs because students were forced to speak only English in class. That is, learners might have more opportunities to practice their English in such environments.

Finally, $34.8 \%$ of the participants considered NESTs had a bigger wealth of vocabulary, which increased the students' chances to acquire more vocabulary. Also, $78.3 \%$ of the participants believed NESTs supplied more information in the English language and its culture, and $60.4 \%$ of the respondents agreed that the teaching style of
NESTs ensured student enjoyment of the lessons. To sum, $60.9 \%$ of the respondents agreed that since intermediate and advanced learners relied less on the Chinese support and needed more opportunities to practice their English, learning with NESTs could be a good choice for them.

Surprisingly, the results revealed that learners generally did not feel anxious when learning from NESTs, which did not coincide with most existing studies. Those researchers suggested that language anxiety might arise when learners encountered native English speakers in English [40,41,42]. Also, some previous studies found the strengths of NNESTs in teaching grammar [27,43,44]; however, NESTs' teaching of grammar and writing were preferred by some participants (about $40 \%$ ) in this study. In addition to being familiarity with certain writing styles, and providing different variations of sentence structures in one specific grammar rule, NESTs might be preferable to the participants because they were usually assigned to teach oracy rather than grammar or writing courses.

As one might expect, Taiwanese university students perceived NESTs' and NNESTs' English education differently; both groups of teachers had their strengths and weaknesses in different aspects of English education. Generally, a high number of the participants (68.5\%) believed a good EFL teacher was someone who had both experience and qualification in teaching English.

\subsection{Research Question 2}

From which group of teachers do Taiwanese university students prefer to learn English, Native English-Speaking Teachers (NESTs) or Non-Native English-Speaking Teachers (NNESTs) and why?

Out of the 28 items, 26 of them (items 1 to 26) were about evaluating the performances of NESTs and NNESTs in English education and two of them (items 27 and 28) were about the participants' general preferences of NESTs and NNESTs. Based on the finding on item 27, the participants had a preference of NESTs over NNESTs in English learning. This finding could be explained by the reasons discussed in the first research question.

The researcher suspected that English learners of different English proficiencies might have different preferences in regard to NESTs' and NNESTs' English teaching. Based on this assumption, the researcher selected four items, items 3, 4, 11, and 27, which may reflect the participants' distinct responses. Figure 1 presents the means of responses from different groups of language learners in terms of English proficiency. On item 3, "I feel motivated when I take course with Non-NESTs," and item 4, "I feel anxious when I take course with NESTs," the means of responses decreased with proficiency levels from beginner to advanced learners. In contrast, on item 11, "I prefer taking oral courses with NESTs because it forces me not to speak Chinese," and item 27, "NESTs are preferable to Non-NESTs and I learn more from them," the means of responses increased with proficiency levels from beginner to advanced level. The findings confirmed the researcher's assumption that NNESTs were more preferable to beginner learners while advanced students preferred to learn from NESTs. 


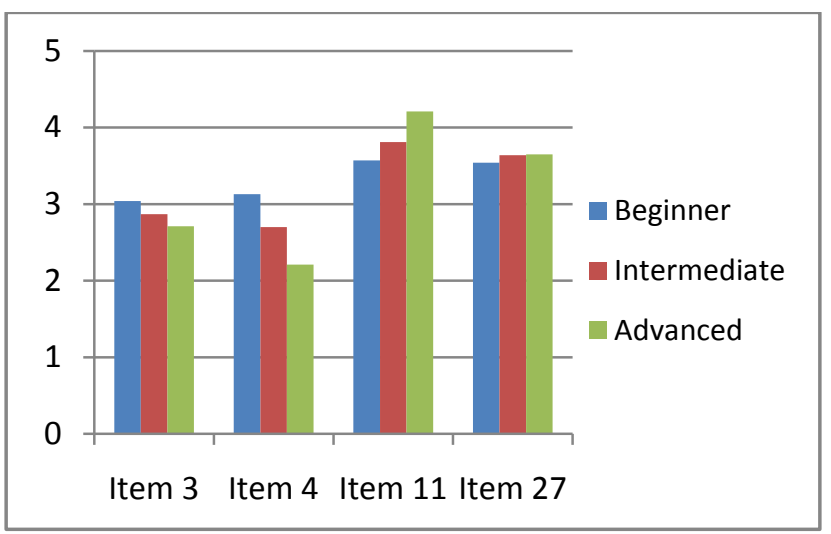

Note. Item 3= I feel motivated when I take course with Non-NESTs. Item 4= I feel anxious when I take course with NESTs.

Item 11= I prefer taking oral courses with NESTs because it forces me not to speak Chinese.

Item $27=$ NESTs are preferable to Non-NESTs and I learn more from them.

Figure 1. Means of the Participants' Responses to Items 3, 4, 11, and 27

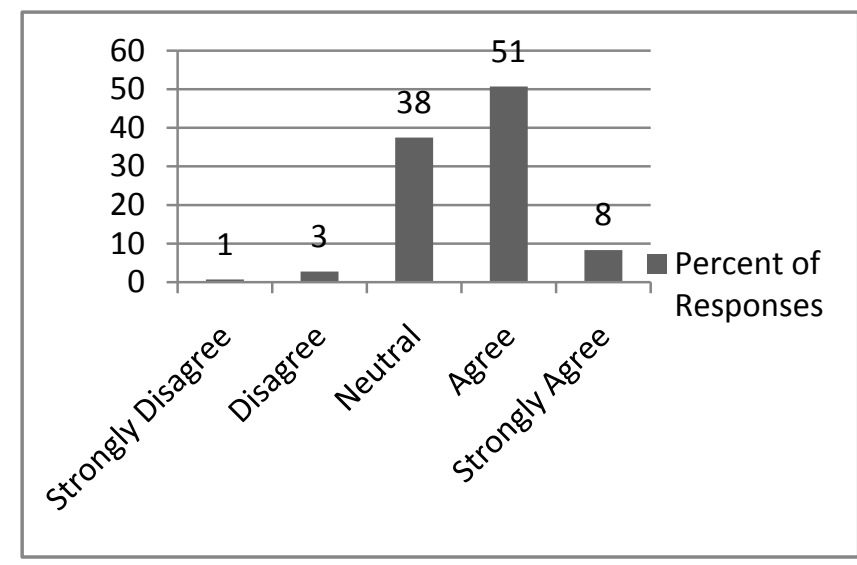

Note. Item 27= NESTs are preferable to Non-NESTs and I learn more from them.

Figure 2. Percentage Distribution of the Female Participants' Responses to Item 27

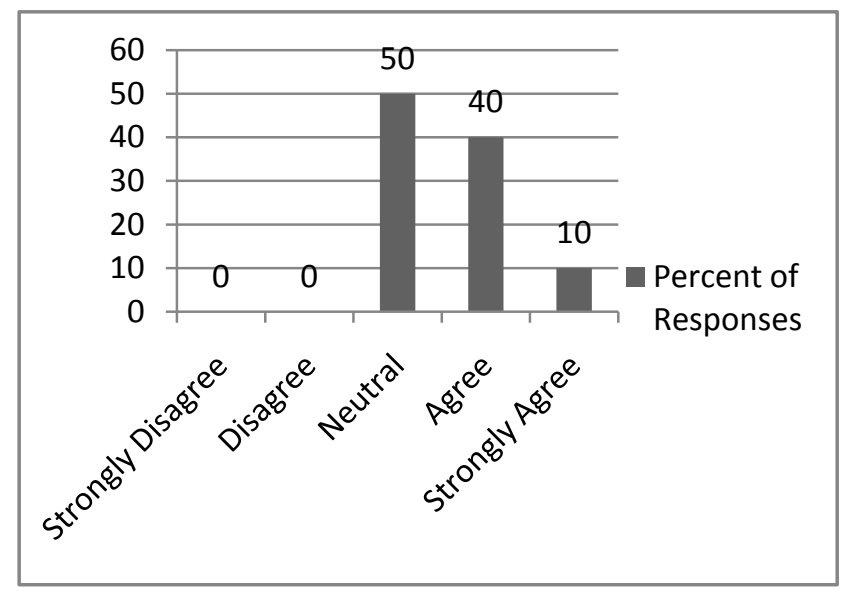

Note. Item $27=$ NESTs are preferable to Non-NESTs and I learn more from them.

Figure 3. Percentage Distribution of the Male Participants' Responses to Item 27

The researcher further investigated whether different genders had preferences over the two groups of teachers. Figure 1 and Figure 2 presented the distributions of female and male participants' responses of overall preferences to
Item 27. As indicated in these two figures, both female and male participants preferred to learn English with NESTs. However, female participants had a stronger preference to learn English with NESTs. That is, there were $59 \%$ of the female participants preferred to learn English with NESTs (Figure 2), while 50\% of the male participants had preferences to learn English with NESTs (Figure 3). Therefore, in this study, the gender did influence the participants' preferences toward the English instruction of NESTs and NNESTs.

Importantly, the response to item 28 showed that about $80 \%$ of the participants suggested the cooperation between of NESTs and NNESTs in English teaching. According to Delli Carpini [45], teacher collaboration was one of the key measures for improving student achievement, effective professional development, and continued school success. Wang's [46] study revealed that "both NESTs and NNESTs had great interest and willingness to team teach, and believed that this collaborative model has pedagogic benefits" (p. 32). More precisely, NESTs and NNESTs both had pros and cons in distinct areas in English as a foreign language (EFL). They were recommended to learn from each other, exchange their teaching experiences, and further work cooperatively to ensure students' academic success. This study supported those existing research findings and further introduced students' perceptions into this issue.

\subsection{Section Three: Students' Learning Experiences with NESTs and NNESTs}

This section provides information about the participants learning experiences they had with NESTs and NNESTs, including both positive and negative experiences. Table 2 presents the languages that subjects used while responding to the two open-ended questions (see items 29 and 30). There were $42.4 \%$ of the participants answered in English, while $57.6 \%$ responded in Chinese. In practice, the researcher translated 50 randomly selected participants' responses from Chinese into English before transcribing the data into Microsoft Word. The selected data was replied in $38 \%$ of English and $62 \%$ of Chinese (see Table 2). All 50 English transcriptions of responses were verified by one doctoral student in an education related major and two NNESTs in Taiwan. Also, 10 respondents received their transcriptions to verify whether or not the English translations matched their answers. After that, the researcher inputted the data into a qualitative data analysis software ATLAS.ti. 7.0. for analyzing.

Table 2. The Participants' Languages Used on Items 29 and 30

\begin{tabular}{lcccccc}
\hline & \multicolumn{2}{c}{ Primary data } & Total & \multicolumn{2}{c}{ Selected data } & Total \\
& English & Chinese & & English & Chinese & \\
\hline Frequency & 78 & 106 & 184 & 19 & 31 & 50 \\
Percentage & 42.4 & 57.6 & 100 & 38 & 62 & 100 \\
\hline
\end{tabular}

Items 29 and 30: Background information of the participants

The two open-ended questions were designed to investigate some learning experiences and additional perceptions of the participants in regard to their NESTs and NNESTs that were not covered in the questionnaire. 
Almost $80 \%$ of the 184 participants responded to the two open-ended questions. Among those who responded, $51.1 \%$ of the respondents made comments on both of the two questions. There were $79.3 \%$ of the participants answered item 30 , and $66.8 \%$ of the participants gave details in item 31 (see Table 3).

Table 3. Descriptive Statistics of Items 29 and 30

\begin{tabular}{ccccccc}
\hline & \multicolumn{2}{c}{ Item 30} & Total & \multicolumn{2}{c}{ Item 31 } & Total \\
& Answer & Blank & & Answer & Blank & \\
\hline Frequency & 146 & 38 & 184 & 123 & 61 & 184 \\
Percentage & 79.3 & 20.7 & 100 & 66.8 & 33.2 & 100 \\
\hline
\end{tabular}

Note. Item29 = Open-Ended Question 1; Item $30=$ Open-Ended Question 2

Items 29 and 30: Gender of the participants

Table 4 shows the participants' gender. Among the 50 participants, $66 \%(n=33)$ were female and $34 \%(n=17)$ were male.

Table 4. Descriptive Statistics of the Participants' Gender Who Attempted Items 29 and 30

\begin{tabular}{ccccc}
\hline \multirow{2}{*}{ Participants } & & \multicolumn{2}{c}{ Gender } & Total \\
& Frequency & 33 & 17 & 50 \\
& Percentage & 66.0 & 34.0 & 100 \\
\hline
\end{tabular}

Items 29 and 30: Age of the participants

Table 5 presents participants' ages as follows: 24 (48\%) of the participants ranged in age from 18 to 20 , and 26 $(52 \%)$ of the respondents ranged in age from 21 to 23 .

Table 5. Descriptive Statistics of the Participants' Age Who Attempted Items 29 and 30

\begin{tabular}{lll}
\hline Age & Frequency & Percentage \\
\hline 18 to 20 & 24 & 48.0 \\
21 to 23 & 26 & 52.0 \\
\hline Total & 50 & 100 \\
\hline
\end{tabular}

Items 29 and 30: Major of the participants

Table 6 distributes participants' majors: 37 (74\%) in the major of Applied English, $8(16 \%)$ in the major of Applied Foreign language and $5(10 \%)$ in the major of Foreign Language and Applied Linguistics.

Table 6. Descriptive Statistics of the Participants' Majors Who Attempted Items 29 and 30

\begin{tabular}{lll}
\hline Majors & Frequency & Percentage \\
\hline Applied English & 37 & 74.0 \\
Applied Foreign Language & 8 & 16.0 \\
Foreign Language and Applied Linguistics & 5 & 10.0 \\
\hline Total & 50 & 100 \\
\hline
\end{tabular}

Items 29 and 30: University level of the participants

Table 7 shows participants' years of university study. Among the 50 participants, 28\% $(n=14)$ were sophomore students, $30 \%(n=15)$ were junior students and $42 \%(n=21)$ were senior students.
Table 7. Descriptive Statistics of the Participants' University Level Who Attempted Items 29 and 30

\begin{tabular}{lll}
\hline University Level & Frequency & Percentage \\
\hline 2 & 14 & 28.0 \\
3 & 15 & 30.0 \\
4 & 21 & 42.0 \\
\hline Total & 50 & 100 \\
\hline
\end{tabular}

Note. 2 = Sophomore Student; 3 = Junior Student; 4 = Senior Student.

Items 29 and 30: The participants' years of learning English

Table 8 shows the distribution of participants' years of learning English. 31 (62\%) participants had eight to10 of years English learning experiences, 15 (30\%) participants had 11 to 13 years of English learning experiences, and 4 $(8 \%)$ respondents had 14 to 16 years of English learning experiences. In general, the average years of experiences were 10.24 years.

Table 8. Descriptive Statistics of the Participants' Years of Learning English Who Attempted Items 29 and 30

\begin{tabular}{ccc}
\hline Years of Learning English & Frequency & Percentage \\
\hline 8 to 10 & 31 & 62.0 \\
11 to 13 & 15 & 30.0 \\
14 to 16 & 4 & 8.0 \\
\hline Total & 50 & 100 \\
\hline
\end{tabular}

Items 29 and 30: The participants' self-rating of overall English proficiency

Table 9 presents students' self-rating of overall English proficiency: $8(16 \%)$ were beginner, $36(72 \%)$ were in an intermediate level, and six (12\%) were in an advanced level. Generally speaking, the majority of the participants viewed their overall English proficiency as intermediate level.

Table 9. Descriptive Statistics of the Participants' Self-Rating of Overall English Proficiency Who Attempted Items 29 and 30

\begin{tabular}{cccccc}
\hline \multicolumn{5}{c}{ English Proficiency Level } \\
\hline \multirow{4}{*}{ Participants } & Feginner & Intermediate & Advanced & Total \\
& Frequency & 8 & 36 & 6 & 50 \\
& Percentage & 16.0 & 72.0 & 12.0 & 100 \\
\hline
\end{tabular}

Items 29 and 30: The numbers of NESTs and NNESTs who taught the participants' English

Table 10 indicates the number of NESTs and NNESTs from whom the participants learned English. The average number of NESTs from whom the participants received English instruction was 4.5. Specifically, $50 \%(n=25)$ of the participants received English instruction from one to three NESTs, 34\% $(n=17)$ of the participants received English instruction from four to six NESTs, $8 \%(n=4)$ of the participants received English instruction from seven to nine NESTs, and $8 \%(n=4)$ of the participants received instruction from over 10 NESTs.

In regard to the numbers of NNESTs from whom the participants learned English, the average number was 9.1. More precisely, one (2\%) participant received English instruction from one to three NNESTs, 12 (24\%) respondents received English instruction from four to six NNESTs, $10(20 \%)$ students received English instruction 
from seven to nine NNESTs, and 27 (54\%) students received English instruction from over 10 NNESTs.

Table 10. Descriptive Statistics of the Numbers of NESTs and NNESTs Who Taught the Participants' English and Attempted Items 29 and 30

\begin{tabular}{ccccc}
\hline $\begin{array}{c}\text { Numbers of } \\
\text { NESTs and } \\
\text { NNESTs }\end{array}$ & Frequency & Percentage & Frequency & Percentage \\
\hline 1 to 3 & 25 & 50.0 & 1 & 2.0 \\
4 to 6 & 17 & 34.0 & 12 & 24.0 \\
7 to 9 & 4 & 8.0 & 10 & 20.0 \\
Over10 & 4 & 8.0 & 27 & 54.0 \\
\hline Total & 50 & 100 & 50 & 100 \\
\hline
\end{tabular}

Items 29 and 30: Courses studied with NESTs and NNESTs by the participants

Table 11 shows the courses the participants were instructed by NESTs and NNESTs. In reference to oracy courses, 50 participants were instructed by NESTs, and 33 students were instructed by NNESTs. In the courses of writing, 14 participants were instructed by NESTs, and 50 students were instructed by NNESTs. In regard to grammar courses, 17 respondents were instructed by NESTs, and 49 participants were instructed by NNESTs. Regarding the courses of vocabulary, 28 students were instructed by NESTs, and 48 participants were instructed by NNESTs. Finally, in regard to American culture courses, 37 participants were instructed by NESTs, and 20 respondents were instructed by NNESTs.

Table 11. Descriptive Statistics of Courses Studied with NESTs and NNESTs by the Participants Who Attempted Items 29 and 30

\begin{tabular}{lcc}
\hline Courses & $\begin{array}{c}\text { NESTs } \\
\text { Frequency }\end{array}$ & $\begin{array}{c}\text { NNESTs } \\
\text { Frequency }\end{array}$ \\
\hline Oracy & 50 & 33 \\
Writing & 14 & 50 \\
Grammar & 17 & 49 \\
Vocabulary & 28 & 48 \\
American Culture & 37 & 20 \\
\hline
\end{tabular}

As shown in the responses, the participants reported that one of the major aspects where NNESTs were superior to NESTs was their sensitivity to students' needs, difficulties, and problems, which were strongly supported by some previous empirical studies $[43,47,48]$. Such ability may be explained by two possible reasons: (1) the sharing of the same mother tongue language and the cultural background between NNESTs and the respondents, and (2) having similar experiences of the language learning process and educational system as the participants. More precisely, NNESTs had gone through the process of learning English as a foreign language, and they were perceived as typical models of successful English learners by the participants.

\section{Conclusion}

Creating a safe and warm environment is always one of the significant factors in improving students' language learning in any aspect of education. In the process of language instruction, this atmosphere may be especially important. Learners have to be comfortable and feel they could make mistakes and take risks during class, so they would able to take in and produce language. The above two positive features of NNESTs confirmed Krashen's [49] affective filter hypothesis, which shows that students who enter into a learning environment with a high motivation and a low level of anxiety in a learning environment are expected to have more chances to be successful learners than those who do not.

Another positive feature associated with NNESTs involved the ability to alternate between learners' first language and English while instructing. For example, NNESTs were able to draw on their first language (L1) knowledge to identify complicated grammar rules or vocabulary for the participants, and the respondents could discuss their ideas of writing assignments in Chinese with NNESTs. In regard to Cummins' [50] iceberg theory, it is believed that the L1 and the target language represent two icebergs which outwardly differed but fused underneath the surface. To be more specific, the two languages operate together through the same central processing system; one language can easily transfer to the other one as long as they are well-developed. Therefore, L1 promotes the students' second or foreign language learning.

Nevertheless, the Hong Kong Ministry of Education announced a policy that English classes should be taught in English only [51] Chen et al. (2011) and Xie [52] also indicated that the English only instruction has become a new trend that more and more universities in China and Taiwan seek to practice. Based on the results of this study, the benefits of using students' L1 with English instruction were clear and remarkable. Administrators, therefore, should be aware of this finding and reconsider its feasibility.

Last but not least, other positive features such as being easy to communicate with, the ability to select appropriate topics to meet the respondents' goals, and taking more responsibility for their works were supported by the participants. Based on these advantages of NNESTs, the participants, in general, suggested that English learners at a beginning level might learn with NNESTs. On the other hand, negative aspects of NNESTs were mostly associated with their oral skills, particularly their Taiwanese accent, their shortage of the knowledge of the English language, their inability to involve the participants in real world settings of language use and their use of test-bounded teaching styles.

From which group of teachers do Taiwanese university students prefer to learn English, Native English-Speaking Teachers (NESTs) or Non-Native English-Speaking Teachers (NNESTs) and why?

The participants' gender and their levels of English proficiency indicated some differences on their preferences toward the English instruction of NESTs and NNESTs. Specifically, although both of the female and male participants showed their preferences toward learning with NESTs over NNESTs, the female participants held a higher preference for NESTs than male participants. Additionally, the participants in higher levels of English proficiency expressed being more interested in learning with NESTs, whereas the respondents in lower levels of English proficiency seemed to have more positive 
perceptions in regard to NNESTs' English teaching. Generally, based on the questionnaire, the participants revealed an overall preference for NESTs over NNESTs. However, the respondents still considered that both NESTs and NNESTs showed strengths and weaknesses in their English teaching which could benefit the participants' English learning in different language skill areas.

Generally speaking, the participants agreed with the significance of teachers' qualifications and experiences; they further suggested co-teaching or working cooperatively between NESTs and NNESTs. According to Medgyes [53], an ideal language learning environment was a "good balance of NESTs and NNESTs, who complement each other in their strengths and weaknesses" (p. 42). Obviously, the participants in this study believed that, under such English learning conditions, the disadvantages of each type of teachers would be minimized while the advantages of both groups would strengthen.

The participants showed positive attitudes in regard to applying students' mother tongue into English teaching of NNESTs. Therefore, Taiwanese NNESTs are recommended to continue the L1 usage of instruction and further learn how to apply it for students' advantages. In addition, the participants considered NNESTs to be successful role models of English learners. Thus, it is hoped that NNESTs can share their own English learning experiences with their students. For example, some effective learning strategies that NNESTs have found during their own English language learning process would be good experiences to share with learners. In addition, some useful solutions to learning problems from NNESTs' own past learning experiences would be another good resource for learners.s

\section{References}

[1] Krashen, S. (2003). Dealing with English fever. Selected Papers form the Twelfth International Symposium on English Teaching (pp.100-108). Taipei: Crane.

[2] Chang, Y. F. (2008). Parents' attitudes toward the English education policy in Taiwan. Asia Pacific Education Review, 9(4), 423-435.

[3] Yip, H. (2011). Pursuing higher education - in English. Taiwan Review. Retrieved from

$\mathrm{http}: / /$ taiwanreview.nat.gov.tw/ct.asp?xItem $=159421 \& \mathrm{CtNode}=13$ 37.

[4] Vargas, T. M. (2012). How to learn English in an English speaking country. Retrieved from

http://www.ehow.com/how_7965782_learn-english-englishspeaking-country.html.

[5] Wood, H. A. (2010). Learning English in an English speaking country. Retrieved from http://EzineArticles.com/5190039

[6] Al-Omrani, A. H. (2008). Perceptions and attitudes of Saudi ESL and EFL students toward native and nonnative English-speaking teachers. (Doctoral dissertation). Available from ProQuest Dissertation and Theses database. (UMI: 3303340).

[7] Braine, G. (1999). Non-native educators in English language teaching. Mahwah, NJ: Lawrence Erlbaum Associates.

[8] Ellis, L. (2002). Teaching from experience: a new perspective on the non-native teacher in adult ESL. Australian Review of Applied Linguistics, 25(1), 71-107.

[9] Mahboob, A. (2004). Native or nonnative: What do students enrolled in an intensive English program think? In L. KammhiStein (Ed.), Learning and teaching from experience: Perspective on nonnative English speaking professionals (pp. 121-147). Ann Arbor, MI: University of Michigan Press.

[10] Medgyes, P. (1999b). The non-native teacher ( $2^{\text {nd }}$ Ed.). Germany: Hueber.
[11] Kramsch, C. (1997). The privilege of the nonnative speaker. Publications of the Modern Language Association of America, 112 , 359-369.

[12] Freudenstein, R. (1991). Europe after 1992: Chances and problems for the less commonly taught languages. FIPLV World News, 55(21), 1-3.

[13] Ngoc, L. V. C. (2009). Teaching efficacy of native and non-native teachers of English in Vietnam: A triangulation of student and teacher perceptions (Master's thesis). Southern Illinois University, Carbondale, IL.

[14] Phillipson, R. (1992). ELT: The native speaker's burden? ELT Journal, 46(4), 340-349.

[15] Clark, E., \& Paran, A. (2007). The employability of non-nativespeaker teachers of EFL: A UK survey. System, 35, 407-430.

[16] Thomas, J. (1999). Voices from the periphery: non-native teachers and issues of credibility. In Braine (Ed.), Non-native educators in English language teaching (pp. 5-15), Mahwah, NJ: Lawrence Erlbaum Associates.

[17] Bulter, Y.C. (2007). How are non-native English-Speaking teachers perceived by young learner? TESOL Quarterly, 41, 731755.

[18] Davies, A. (2003). The native speaker: Myth and reality. Clevedon, England: Multilingual Matters.

[19] Lee, J. (2005). The native speaker: An achievable model? Asian EFL Journal, 7(2).

[20] Barratt, L. \& Kontra, E. (2000). Native English-speaking teachers in cultures other than their own. TESOL Journal, 9(3), 19-23.

[21] Benson, P. (2012). Learning to teach across borders: Mainland Chinese student English teachers in Hong Kong schools. Language Teaching Research, 16(4), 483-499.

[22] Medgyes, P. (2001). When the teacher is a non-native speaker. Teaching pronunciation, 429-442.

[23] Modiano, M. (1999) International English in the global village. English Today, 15(2), 22-28.

[24] Moussu, L. \& Llurda, E. (2008). Non-native English-speaking English language teachers: History and research. Language Teaching, 41(3), 315-348.

[25] Sommers, S. (2005). Students experience with foreign native speaker English teachers. Retrieved from http://scottsommers.blogs.com/taiwanweblog/2005/07/students_ex peri.html.

[26] Wu, K. \& Ke, C. (2009). Haunting native speakerism? Students' perceptions toward native speaking English teachers. English Language Teaching, 2(3), 44-52.

[27] Cheng, Y. L. \& Braine, G. (2007). The attitudes of university students towards non-native speaker English teachers in Hong Kong. RELC Journal, 38(3), 257-277.

[28] Cook, V. (2005). Basing teaching on the L2 user. In E. Llurda (Ed.), Non-native language teachers: Perceptions, challenges and contributions to the profession (pp. 47-61). New York: Springer.

[29] Modiano, M. (2005). Cultural studies, foreign language teaching and learning practices, and the NNS practitioner. In E. Llurda (Ed.), Non-native language teachers: Perceptions, challenges, and contributions to the profession (pp. 25-43). New York: Springer.

[30] Medgyes, P. (1992). Native or nonnative: who's worth more? ELT Journal, 46(4), 340-349.

[31] Tang, C. (1997). The identity of the nonnative ESL teacher: On the power and status of nonnative ESL teachers. TESOL Quarterly, 31(3), 557-580.

[32] Shaw, P. A. (1979). Handling a language component in a teachertraining course. Modern English Teacher, 3, 12-15.

[33] Widdowson, H. G. (1992). ELT and EL teachers: Matters arising. ELT Journal, 46(4), 333-339.

[34] Boyle, J. (1997). Native-speaker teachers of English in Hong Kong. Language and Education, 11(3), 163-181.

[35] Canagarajah, A. S. (1999). Interrogating the "native speaker fallacy": non-linguistic roots, non-pedagogical results. In G. Braine (Ed.), Non-native educators in English language teaching (pp. 77-92). Mahwah, NJ: Erlbaum.

[36] Moussu, L. (2010). Influence of teacher-contact time and other variables on ESL students' attitudes towards native-and nonnativeEnglish-speaking teachers. TESOL Quarterly, 44(4), 746-768.

[37] Moussu, L. (2006). Native and nonnative English speaking English as a second language teachers: Student attitudes, teacher self-perceptions, and intensive English program administrator beliefs and practices (Doctoral dissertation). 
[38] Arva, V. \& Medgyes, P. (2000). Native and non-native teachers in the classroom. System, 28(3), 355-372.

[39] Trochim, W. M. (2006). Survey Research. Research methods knowledge base. Retrieved from: http://www.socialresearchmethods.net/kb/intrview.php.

[40] Chan, S. H., Abdullah, A. N., \& Yusof, N. B. (2012). Investigating the construct of anxiety in relation to speaking skills among ESL tertiary learners. 3L; Language, Linguistics and Literature, 18(3), $155-166$

[41] Chang, M. (2012). A study of foreign language classroom anxiety at Taiwanese university. In W. M. Chan, N. K. Chin, S. Bhatt, \& I. Walker (Ed.), Perspective on individual characteristics and foreign language education (pp. 317-330). Boston: Walter de Gruyter.

[42] Docan-Morgan, T. \& Schmidt, T. (2012). Reducing public speaking anxiety for native and non-native English speakers: The value of systematic desensitization, cognitive restructuring, and skills training. Cross-Cultural Communication, 8(5), 16-19.

[43] Lipovsky, C. \& Mahboob, A. (2010). Appraisal of native and nonnative English speaking teachers. In A. Mahboob (Ed.), The NNEST lens: Nonnative English speakers in TESOL (pp. 154-179). Newcastle upon Tyne, England: Cambridge Scholars.

[44] Pacek, D. (2005). "Personality not nationality": Foreign students" perceptions of a non-native speaker lecturer of English at a British university. In E. Llurda (Ed.), Non-native language teacher: Perceptions, challenges and contributions to the profession (pp. 243-262). New York, NY: Springer.

[45] Delli Carpini, M. (2008). Teacher collaboration for ESL/EFL academic success. Internet TESL Journal, 14(8). Retrieved from
http://iteslj.org/Techniques/DelliCarpiniTeacherCollaboration.html.

[46] Wang, L. I. (2012). Preparing NESTs and NNESTs for team teaching at the pre-service level. Studies in Literature and Language, 4 (1), 32-37.

[47] Lasagabaster, D. \& Sierra, J. M. (2005). What do students think about the pros and cons of having a native speaker teacher? In E. Llurda (Ed.), Non-native English teachers: Perceptions, challenges and contributions to the profession (pp. 217-241). New York: Springer.

[48] Ma, L. P. F. (2009). Student perceptions of native English teachers and local English teachers. In A. Mahboob \& C. Lipovsky (Eds.) Studies in applied linguistics and language learning (pp. 325-348). Newcastle upon Tyne, England: Cambridge Scholars.

[49] Krashen, S. (1982). Principles and practice in second language acquisition. London: Prentice-Hall International.

[50] Cummins, J. (2001). Negotiating identities: Education for empowerment in a diverse society. Ontario, CA: California Association of Bilingual Education.

[51] Ma, L. P. F. (2012). Advantages and disadvantages of native- and nonnative-English-speaking teachers: Student perceptions in Hong Kong. TESOL Quarterly, 46(2), 280-305.

[52] Xie, Y. (2005). A study of teaching financial courses in English. Journal of Guangdong University of Foreign Studies, 16(4), 83-86.

[53] Medgyes, P. (1996). Native or nonnative: who's worth more? In T. Hedge \& N. Whitney (Eds.), Power, pedagogy \& practice (pp. 3142). Oxford: Oxford University Press.

[54] Medgyes, P. (1994). The non-native teachers. London: MacMillan. 